lung lying in front of the heart. With other causes of mediastinal shift the heart should be easily seen unless there is air in front of it; in diaphragmatic hernia the heart should be visible in its displaced position ${ }^{2}$ until bowel gas accumulates.

Ultrasound is therefore a new technique to diagnose pneumothorax, but it is clearly not the best, and any suspicion should be confirmed using conventional methods before treatment. Nevertheless, pneumothorax can be a catastrophic complication of hyaline membrane disease, and those performing echocardiography on sick, ventilated neonates should be aware of this, so if the heart is difficult to visualise, or is laterally displaced, the attending clinicians can be informed immediately.

J R SKINNER D W A MILLIGAN Special Care Baby Unit, Newcastle General Hospital,
ewcastle upon Tyme NE4 $6 B E$ Newcastle upon Tyne NE4 $6 B E$ S HUNTER
Department of Paediatric Cardiology, Freeman Hospital, High Heaton,

Newcastle upon Tyme NE7 7DN

Dr J Skinner is supported by the National Heart Research Fund.

1 Skinner JR, Hunter S, Hey EN. Pulmonary artery pressure in hyaline membrane disease. Pediatr Res 1990;28:286.

2 Crawford DC, Wright VM, Drake DP, Allan LD. Fetal diaphragmatic hernia: the value of fetal echocardiography in the prediction of postnatal outcome. Br $\mathcal{Y}$ Obstet Gymaecol 1989; post $705-10$.

Fluconazole in neonatal disseminated candidiasis

SIR,-We report the case of an infant, born at 28 weeks' gestation weighing $900 \mathrm{~g}$, who on the 22nd day of life had thrombocytopenia and leukocytosis. Urine and blood cultures yielded Candida albicans. Amphotericin B was raised to $1.0 \mathrm{mg} / \mathrm{kg} /$ day by day 4 and on day 5 , added and a broviac catheter inserted. Peripheral and central blood cultures on the 7th, $14 \mathrm{th}$, and 18th days of treatment with and cultures of abscesses on the forehead and arm yielded $C$ albicans on day 18 . Ultrasound of the kidneys, head, and abdomen as well as an ophthalmologic evaluation, gallium scan, and culture of the cerebrospinal fluid were negative. Amphotericin $B$ and flucytosine were discontinued after 18 and 12 days, respectively. The catheter was removed and intravenous fluconazole (6 $\mathrm{mg} / \mathrm{kg} /$ day $)$ initiated. ${ }^{1}$ The catheter was replaced on day 4 of fluconazole. On day 5 of fluconazole peripheral and central blood cultures were flucytosine $25 \mathrm{mg} / \mathrm{kg}$ every six hours was amphotericin B continued to yield $C$ albicans,

negative for $C$ albicans. Fluconazole was discontinued after 20 days with cultures remaining negative during four months of follow up.

Fluconazole serum concentrations three hours after the infusion and before the next dose on day 7 of treatment were 10.30 and $6.98 \mu \mathrm{g} / \mathrm{ml}$. Amphotericin B concentrations were $0.21 \mu \mathrm{g} / \mathrm{ml}$ on day 14 of treatment and $0.12 \mu \mathrm{g} / \mathrm{ml} 30$ days after discontinuation. A first order, one compartment model ${ }^{2}$ resulted in the following pharmacokinetic parameters for fluconazole:

$$
\begin{gathered}
t_{1 / 2} \beta=37 \cdot 4 \text { hours, } \mathrm{aV}_{\mathrm{d}}=1 \cdot 2 \mathrm{l} / \mathrm{kg}, \\
\mathrm{CL}=0.02 \mathrm{l} / \mathrm{kg} / \text { hour. }
\end{gathered}
$$

(Where $t_{1 / 2} \beta$ is terminal elimination half life, $\mathrm{aV}_{\mathrm{d}}$ is the apparent volume of distribution, and $C L$ is clearance.) This indicates a larger $\mathrm{aV}_{\mathrm{d}}$ and a longer $\mathrm{t}_{1 / 2} \boldsymbol{\beta}$ as compared with adults $\left(0.7(0.06) 1 / \mathrm{kg}\right.$ and $22(3.5)$ hours). ${ }^{3}$

The activities of four antifungal drugs against the isolate of $C$ albicans from this patient are indicated in the table. ${ }^{4}$ These results do not necessarily reflect therapeutic efficacy. Because of the presence of amphotericin B during and after fluconazole, one could speculate that fluconazole and amphotericin B acted synergistically. Other factors may have also helped to eradicate $C$ albicans. Further studies of fluconazole's efficacy in immunocompromised adults with invasive fungal disease are needed before studies in neonates are considered.

$$
\begin{array}{r}
\text { D B WIEST } \\
\text { S L FOWLER } \\
\text { S S GARNER } \\
\text { D R SIMONS } \\
\text { Departments of Clinical Pharmacy } \\
\text { and Pediatrics and Division of } \\
\text { Pediatric. Infectious Disease, } \\
\text { Medical University of South Carolina, } \\
171 \text { Ashley Avenue, } \\
\text { Charleston, } \\
\text { South Carolina, } \\
\text { USA 29425-0810 }
\end{array}
$$

1 Viscoli C, Castagnola E, Corsini M, et al. Flu(n) f Clin Microbiol Infect Dis 1989;8:925-6.

2 Gibaldi M, Perrier D. Pharmacokinetics. 2nd Ed. New York: Marcel Dekker, 1982.

3 Humphrey MJ, Jevons S, Tarbit MH. Pharmacokinetic evaluation of UD-49,858, a metabocokinetic evaluation of UD-49,858, a metabo-
lically stable triazole antifungal drug, in lically stable triazole antifungal drug, in
animals and humans. Antimicrob Agents animals and humans.

4 Rinaldi MG, Howell AW. Antifungal and antimycotic laboratory evaluation. In: Wentworth $\mathrm{BB}$, ed. Diagnostic procedures for mycotic and parasitic infections. 7th Ed. Washington, DC: American Public Health Association, 1988: 325-56.

\section{Chronic vitamin D overdosage: a reminder}

SIR,-After the reported increased incidence of rickets in Asian children in the late 1970s there has been increased awareness of the need for vitamin D supplementation. ${ }^{1}$ This is now being recommended by the Department of Health and usually given together with other vitamins in multivitamin preparations.

Minimum inhibitory concentration and minimum lethal concentration of four antifungal drugs (concentrations in $\mu \mathrm{g} / \mathrm{ml}$ )

\begin{tabular}{lcccc}
\hline & Amphotericin & Fluconazole & Itraconazole & Schering \\
& & & 39304 \\
\hline Minimum inhibitory concentration: & $<0.01$ & $<1.25$ & \\
24 hours & $<0.29$ & 5.00 & 0.02 & $<0.63$ \\
48 hours & & 0.02 & 2.50 \\
Minimum lethal concentration: & 0.58 & $>80.00$ & $>10.00$ & $>80.00$ \\
24 hours & 2.31 & $>80.00$ & $>10.00$ & $>80.00$ \\
\hline 48 hours & & & \\
\hline
\end{tabular}

Parents are able to obtain their supply through their local child health clinics under the Welfare Food Scheme. ${ }^{2}$ There are also many alternative preparations available without a prescription via other sources, however, including chemists and health shops. Therefore, self medication without professional supervision is a potential danger. Chronic poisoning as a result of inappropriate administration of vitamins is rarely reported now (there has been no case reported in the English language literature in the past 10 years) but we were recently presented with a case of gross hypercalcaemia due to vitamin $D$ overdosage.

A 6 month old Indian boy was admitted with a six day history of vomiting, constipation, and increasing apathy. Examination revealed a drowsy, listless child with signs of $5-10 \%$ dehydration. Plasma electrolyte concentrations on admission showed a urea of $7 \cdot 4$ $\mathrm{mmol} / \mathrm{l}$, sodium $148 \mathrm{mmol} / \mathrm{l}$, potassium $2 \cdot 9$ $\mathrm{mmol} / \mathrm{l}$, and a grossly raised calcium concentration of $5.86 \mathrm{mmol} / \mathrm{l}$.

Subsequent investigations showed an appreciably increased vitamin D concentration (25hydroxycholecalciferol) at $2226 \mathrm{nmol} / \mathrm{l}$ (normal 10-120 nmol/1) and undetectable parathyroid hormone. On close questioning, his parents admitted to administering a compound preparation of vitamins $A, C$, and D since the age of 4 months, and as he had refused to take these from the dropper, they poured the vitamin into his mouth directly from the bottle instead! They had obtained their vitamin supply from a chemist privately and had received no professional supervision of administration.

The baby was given intravenous fluids for five days and also commenced on a low calcium, low vitamin $\mathrm{D}$ diet. He was discharged home on day 12 . His calcium returned to normal by day 19 but his vitamin D concentration remained raised for over six months. Follow up at one year showed moderate global developmental delay.

This case illustrates the dangers of unsupervised vitamin supplementation. To prevent further incidents, tighter control over availability of vitamins and improved public awareness of the potential dangers of vitamin overdosage would be helpful. Health professionals should also aim to improve supervision.

$$
\begin{array}{r}
\text { M L B KO } \\
\text { M M LIBERMAN } \\
\text { Department of Paediatrics, } \\
\text { Northwick Park Hospital, } \\
\text { Harrow HAI 3U于 } \\
\text { M SALZMANN } \\
\text { Deparment of Clinical Chemistry, } \\
\text { Northwick Park Hospital, } \\
\text { Harrow HAI 3U于 }
\end{array}
$$

1 Anonymous. Rickets in Asian children. $B M Y$ 1979;i:1744.

2 Department of Health and Social Security. Present day practice in infant feeding. 3rd Report. London: DHSS, 1988: 35-6, 50 .

\section{The paediatric departmental library}

SIR,-Dr Clayden is, I fear, somewhat over optimistic when he suggests that we are 'on the brink of a breakthrough in data retrieval' by which we will 'access original articles and learned reviews at the touch of a few buttons ... so the medical library will pass into the mists of memory'. ' Clearly this sort of thing is on the horizon. I already spend nearly as much time advising doctors on suitable 
index terms for searching MEDLINE on compact disc as I do guiding them around the vagaries of the library catalogue. My colleagues and $I$ are, in fact, slowly adapting ourselves to the fact that what we have been doing is storing and retrieving things-books, journals, papers, etc, while what our customers often want is not things, but information. Up till now, however, much of the revolution which is leading to the 'death of the book' and the end of the scientific journal, has consisted of books and journal articles. I wonder if there is any evidence of Caxton or Gutenberg circulating illuminated manuscripts on 'the death of the illuminated manuscript' during the last communications revolution? I also wonder if I would have come across Dr Clayden's opinions if he had circulated them by electronic mail rather than in the form of a journal article.

More seriously, a cause for concern is the common delusion among doctors that because information is going to become available in an electronic form it is somehow going to be 'free'. A quick glance at the organisations currently involved should convince them that this is not the case-DIALOG, which is a subsidiary of the Lockheed Corporation, Pergamon Press, EM-BASE which is owned by Elsevier, and DATA-STAR which is owned by the Swiss Radio Corporation! It seems to me to be much more likely that those hospitals and medical schools which can make a major financial commitment to information systems will end up being much better served than they are at present, but that isolated specialists working in poorer parts of this country, let alone those in Bulgaria or Bangladesh, are going to be considerably more deprived of information than they are at present. Much of the technology already exists, but we do not have the staff to offer it. Brophy tells of a new polytechnic lecturer who had arrived from a commercial research organisation in which he had had a personalised publication bulletin every Monday, with all the documents he ticked in it delivered to his desk by Friday, and a regular visit from his information officer to make sure the document supply was on target. ${ }^{2}$ The polytechnic had the technology to do the same, but it had an average of one subject librarian to 1100 readers, and is very unlikely to make the investment in people, as well as in equipment, necessary to take advantage of the technology.

One thing which puzzled me was Dr Clayden's implicit assumption that he is going to retain his functions, and even his title, during the information upheaval he predicts. The 'death of the book' surely implies the abolition of the 'reader in paediatrics'. Even if he changes his title to that of the less euphonious 'VDU-scanner in paediatrics' it seems to me to be much more likely that I will be able to stagger on as a sort of glorified jukebox attendant, but that many of Dr Clayden's functions can be taken over by an Expert System, on the one hand, and by far lower paid counsellors on the other. I hope and expect that he and I will get safely through to retirement all right, but I have doubts about our successors.

MARTIN GUHA Library, Library,
Institute of Psychiatry,
De Crespigmy Park,
Demomark Hill, Denmark Hill,
London SES $8 A F$

1 Clayden G. The paediatric department library. Arch Dis Child 1991;66:370.
2 Brophy P. Organising for change in polytechnic libraries. Librany Association University College and Research Newsletter 1991;32:10-6.

\section{Dr Clayden comments:}

I would support Mr Guha in his defence of the librarians' future. I was merely suggesting in my brief article that the medical library as a place might disappear. The librarians' role of custodians of information systems and experts in retrieval is already taking over from the role of guardians of books. We should not lose sight of the liberation from memorising facts which the accessibility of massive databases is increasingly allowing. I would imagine most patients would prefer their doctor to be expert in using data to solve their problems than merely being able to retrieve from their own memories the list of facts about a particular illness. Similarly, the librarian who is expert in retrieval of information is more vital than those expert in the effect of climate on the degeneration of books and manuscripts. It is inevitable that I should use a journal to communicate my opinions at this stage as the availability of electronic newsboards has been priced out of the market so far. Similarly, I cannot imagine that Bell attempted to phone his friends about modifications to his invention in the early years either.

I cannot agree in the long term with $\mathbf{M r}$ Guha's anxiety about the developing world. An out of date book is perhaps as dangerous as no book at all. How many remote areas of the world are unable to receive radio broadcasts now? It is therefore easy to foresee the future of sonar powered computers receiving satellite transmitted signals to update databases and expert systems through the world.

On the personal side, I do have to admit to an early fear of books bred (or is it bread) as a result of a degree of dyslexia in childhood. Although the telephone and word processor may be our mode of communication, I welcome the humanity which shines through these contacts by friendly and supportive librarians as much as $\mathbf{M r}$ Guha and I will value that of the future doctors into whose hands we will inevitably fall. Let up hope that their kindness and wisdom are also strengthened by all the powers of science and technology available in that hopefully distant time.

\section{Squatting and urinary tract infection}

SIR,-We read with interest the article by Hellström et al on the association of urinary symptoms and previous urinary tract infection. ${ }^{1}$ Hellström et al found urinary tract infection in $15(37 \%)$ of 41 children with squatting. We agree that urinary tract infection is common in children with squatting. ${ }^{2}$ In the past 22 months we identified 16 children who presented with squatting at least once per week. The average age at our assessment was 77 months, range 47 to 126 months. There were 15 girls and one boy. The table shows the frequency of chronically holding the urine to the last minute and urinary tract infection in these children. None of the children had encopresis, a gait disturbance, a palpable defect in the lumbosacral spine, or an abnormal neurological examination.

Nine of the 16 children in our series had either a retrograde voiding cystourethrogram taken or cystoscopy performed. Four children had mild vesicoureteric reflux, two had trabeculated bladder (one also had a bladder
The frequency of chronically holding the urine to the last minute and urinary tract infection in children with squatting (results are number (\%) of children)

\begin{tabular}{|c|c|c|}
\hline & \multicolumn{2}{|c|}{ Frequency } \\
\hline & $\begin{array}{l}\text { Present } \\
\text { series } \\
(n=16)\end{array}$ & $\begin{array}{l}\text { Hellström } \\
\text { et } \text { al }^{\prime} \\
(n=41)\end{array}$ \\
\hline $\begin{array}{l}\text { Chronic holding of urine } \\
\text { Urinary tract infection }\end{array}$ & $\begin{array}{l}11(69) \\
13(81)\end{array}$ & $15(37)$ \\
\hline
\end{tabular}

diverticulum), and one had urethral stenosis. Only two children had normal results on these studies and both of these children had a history of chronically holding the urine to the last minute. Four of the five children who did not hold their urine to the last minute had abnormal results on the studies.

Hellström et al questioned whether symptoms of bladder dysfunction or urinary tract infection come first and whether they develop in a causal relationship. We believe that both urinary tract infection and squatting develop consequent to a number of clinical conditions including chronically holding the urine to the last minute, detrussor sphincter incoordination, or urethral obstruction. Chronically holding the urine to the last minute may become a habit in some children and should be differentiated from children with urgency who do respond promptly to the signals of the need to void. In the former case, parents typically observe these children dancing around, fidgeting, or holding themselves, whereas in the latter case, the sensation comes on suddenly without any warning.

Instructing children to respond promptly to the signals of the need to void, take their time to completely empty the bladder, and void at least every two hours during the day should be part of the treatment plan for children with either urinary tract infection or squatting.

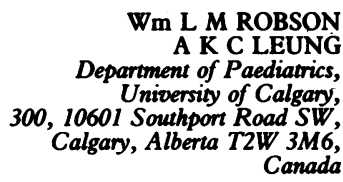

1 Hellström A, Hanson E, Hansson S, Hjälmås K, Jodal U. Association between urinary symptoms at 7 years old and previous urinary tract infection. Arch Dis Child 1991;66:232-4.

2 Robson WLM. Urinary tract infection in children: diagnosis and treatment. Canadian Family Physician 1990;36:1597-600.

\section{Gastro-oesophageal reflux and the lung}

SIR,-I read with great interest the annotation by Professor Simpson and Dr Hampton about the inter-relationships between respiratory disorders and gastro-oesophageal reflux. ${ }^{1}$ The authors did not mention an important group of children in whom respiratory disease and reflux may coexist, namely those with cystic fibrosis. The association between these conditions first came to light $\mathbf{1 0}$ years ago when two children were reported in whom gastrooesophageal reflux disease with recurrent aspiration had been diagnosed, but who were subsequently discovered to have cystic fibrosis. ${ }^{2}$ A study from 1985 described a questionnaire survey of 65 patients with cystic fibrosis in whom one quarter reported heartburn and/or regurgitation. ${ }^{3}$ A large scale, prospective study of the incidence of reflux in cystic 